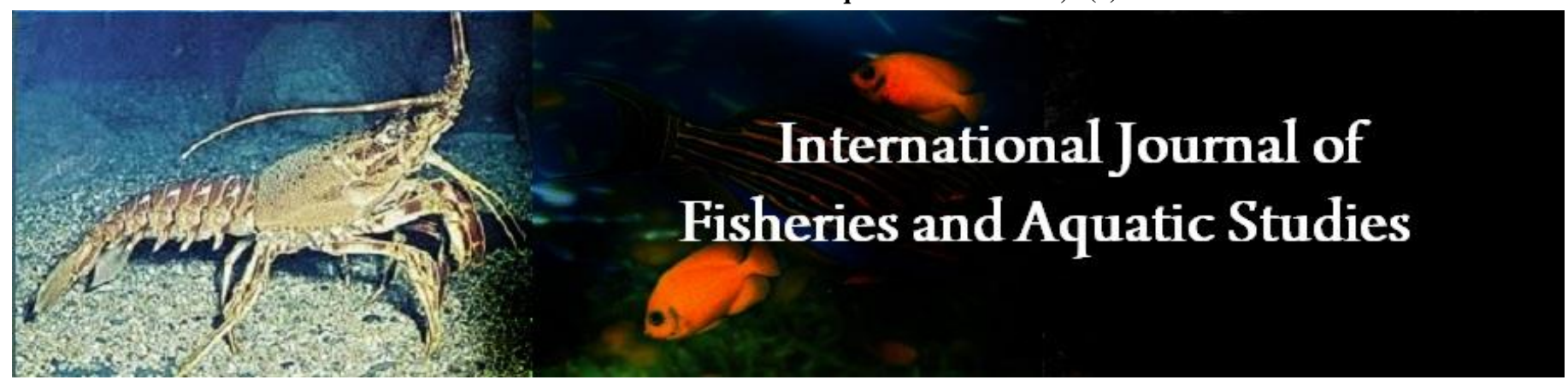

ISSN: 2347-5129

IJFAS 2015; 2(4): 17-22

(C) 2015 IJFAS

www.fisheriesjournal.com

Received: 05-01-2015

Accepted: 20-01-2015

Shanchita Zaman Chowdhury Department of Fisheries and Marine Bioscience, Jessore University of Science and Technology, Jessore-7408, Bangladesh.

Md. Mer Mosharraf Hossain Department of Fisheries and Marine Bioscience, Jessore University of Science and Technology, Jessore-7408, Bangladesh.

Correspondence

Md. Mer Mosharraf Hossain Department of Fisheries and Marine Bioscience, Jessore University of Science and Technology, Jessore-7408, Bangladesh.

\section{Isolation and characterization of internal parasites in snakehead}

\section{Shanchita Zaman Chowdhury, Md. Mer Mosharraf Hossain}

DOI: https://doi.org/10.22271/fish.2015.v2.i4a.331

\section{Abstract}

This study deals with the isolation and characterization of parasitic infection in Channa punctata collected from different water bodies in Jessore, Bangladesh. Skins, gills, intestine, kidney, liver were observed for finding parasites. In total thirty parasites were identified under five species from fifty experimental fish. Different types of parasites such as cestodes, platyhelminth, nematode, acanthocephalan and liver fluke were found from experimental fish. The high incidence of parasite infection in Channa punctatus was found in the river, lake or beel area compares with the farmed fish.

Keywords: Isolation, Characterization, Internal Parasites, Channa Punctate

\section{Introduction}

The snake headed fish Channa punctatus is the representative of the Channiform family Channidae which is the most important species of inland fisheries of Bangladesh. Among other snake headed fishes (C. striatus, $C$. marulius, $C$. barca, and $C$. orientalis) Channapunctatus is one of the most popular fish with delicious taste. This fish is mostly served as a curry dish. It is mud-loving fish and due to its food habit, it can act as an intermediate host for many helminth parasites. However, this fish has a very good commercial value in Bangladesh as well as in Indian subcontinent.

Parasitic infestation has harmful influence for fish health that inhibits the normal growth of the fishes and outbreaks high mortalities. The declination of Channa punctatus is regarded as its susceptibility to Epizootic Ulcerative Syndrome disease ${ }^{[1]}$ and over exploitation and habitat degradation ${ }^{[2]}$. Air breathing Channa punctatus can live without water for a long time without using any preservatives, this fish increasingly being used for freshwater aquaculture in Bangladesh to diverse favorable cultural characteristics. But the effects of parasites are one of the factors hindering high production of fish ${ }^{[3]}$. Also, the parasitic infections of this experimental fish results in economic losses due to not only mortality, but also treatment costs, decreasing growth that reduces the expansion of aquaculture.

Parasites that infest fish health, growth and survival. In Bangladesh parasitic study has been conducted in both freshwater and marine environment where several protozoan, helminthes and crustacean parasites were recorded in different fish species. Some studies of Channapunctatus fish have been done in biology, mainly in the breeding program of this fish [4], and histopathology of diseased fish ${ }^{[5,6]}$. Infestation of helminth parasites and histopathological changes in snake headed fishes has been recorded.

A little knowledge about the distribution, prevalence, parasitic intensity, pathogenic effects and control of most of the parasitic diseases in natural population of freshwater fish has been obtained particularly in the Jessore region of Bangladesh. As the Channa punctatus is most popular fish in Jessore as well as throughout the country, their abundance is reducing due to over exploitation, environmental stress and the occurrence diseases. Though a lot of fish species are available in the water body of Jessore and very little parasitic investigation has been done so far. As a consequence, parasitic infestation has been provoked in fisheries stock over the time. Therefore, therefore the parasitic infestation in aquaculture ponds and wild stock is the great opportunity to study to find out the percentage of prevalence and control measures. Jessore is one of the most pioneer on seed producing zone in Bangladesh, especially for finfish since 1967. 
The present work has been undertaken to investigate the different parasite communities, and to find out the prevalence and intensity of infestation to Channa punctatus with different habitat of varying water quality in Jessore.

\section{Materials and Methods}

\subsection{Experimental Fish \& Sites}

A total of fifty individuals of Channa punctatus (average weight $45 \pm 10 \mathrm{gm}$ ) were collected randomly from different villages around Jessore city during the period of August, 2013 to January, 2014. Collected fish samples were brought into the fisheries laboratory of Jessore University of Science \& technology, Jessore and kept them in well washed aquarium with chlorine with adequate amount of water, good aeration system and room temperature $\left(25-30{ }^{\circ} \mathrm{C}\right)$.

\subsection{Experimental Procedure}

Fish samples were taken in live condition, weighted, took the total length by scale and killed by hand and examined immediately for parasitological study using photographic microscope. A clean spatula was held to the body of each individual and it was drawn backwards towards the tail in a smooth movement and lifting off a small amount of mucous from the different sites of the body for investigating parasites from skin. Later on, for each sites, mucous scrapings placed on a clean glass slides and examined under the $4 x, 10 x$ and $40 x$ lenses of the photographic microscope for observing the presence of parasites. In gill biopsy, a fine pair of scissors was used to cut open the operculum from both sides to reveal the operculum cavity.

\subsection{Internal Observation}

Gill filaments were taken out by cutting off the two ends of the gill arches, and kept on petridishes. Furthermore, small sample of gills was made by splitting up gill filaments using fine scissors and observed under microscope. Each fish was dissected with a fine scissors used to make an incision along the mid-ventral line of the body to find out the parasites from the internal organs. All internal organs like liver, kidney, stomach, spleen, gastrointestinal track and anal cavity were investigated through a microscope and separated by needle and forceps. The intestines were carefully opened out by an incision from the body and put into a petridish. Sometimes larger nematodes (roundworms) were visible in naked-eyes lying in the body cavity with their heads buried in the intestines and were quickly isolated using forceps, fixed on glass slide with glycerin. All the organs are kept on petridishes and viewed under several microscopic lenses.

All the isolated parasites were fixed in glass slides with glycerin. Some parasites are virtually transparent, smaller in size. In that case, we had to scan slowly by adjusting the microscope condenser power higher to lower. Microscopic picture of all the isolated parasites were taken by camera of the microscope as well as high megapixel camera and the pictures were taken in different view.

\subsection{Parasitic Preservation}

Isolated parasites were then preserved in a glass container. Parasites were preserved with $35 \%$ formalin solution and $10 \%$ glycerine that kept in glass containers in vitro analysis.

\section{Results}

\subsection{Identification and characterisation of Parasites Characteristics of nematode}

Bilaterally symmetrical, and vermiform.

- Body has more than two cell layers, tissues and organs.

- Body cavity is a pseudocoel, body fluid under high pressure.

- Body possesses a through gut with a subterminal anus.

- Body covered in a complex cuticle.
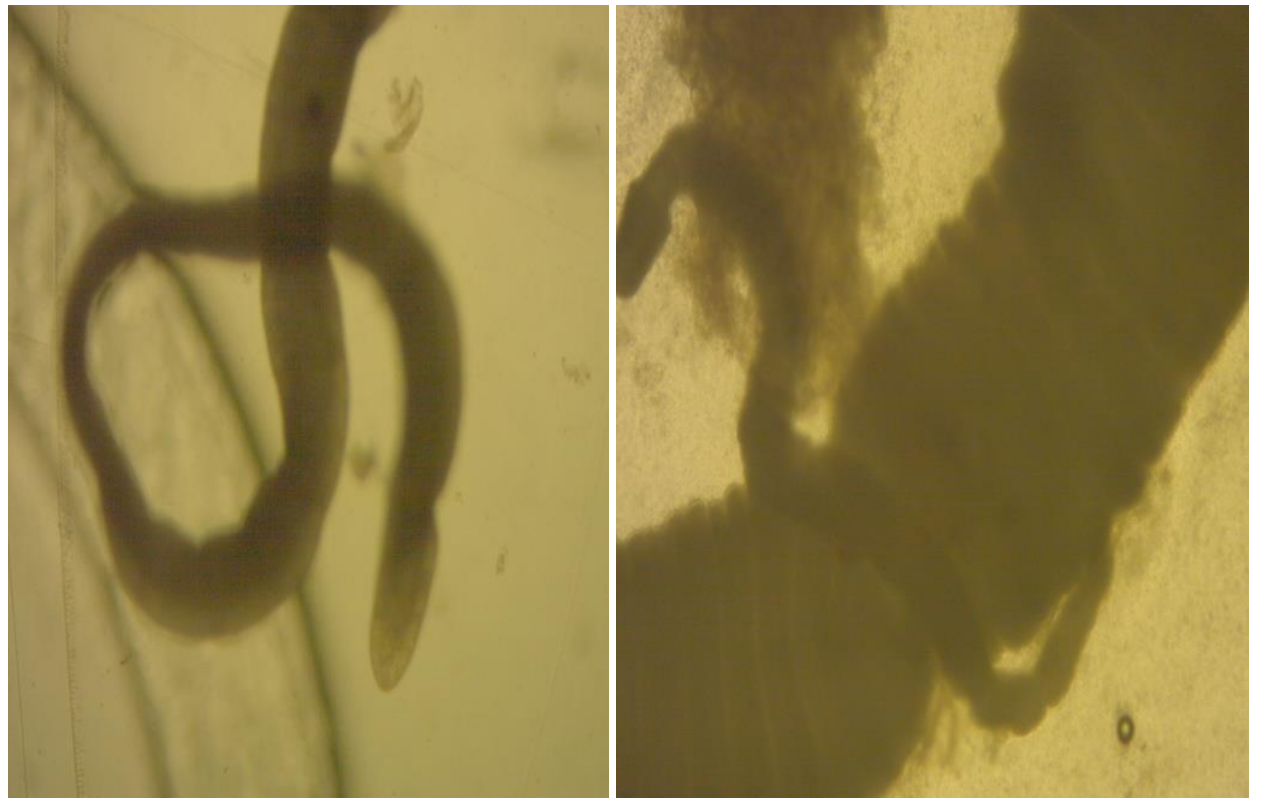

Fig 1: Nematode (Procamallanus laevionchus) in intestine of Channa punctate

\section{Characteristics of cestodes:-}

- Cestodes are long, flat, ribbon-like organisms commonly called tapeworms.

- The head, or scolex, has one or more hooked suckers for firm attachment to the host.
- Behind the head is the neck, which is the growing region. The body consists of segments, each containing reproductive organs.

- There is no digestive system. The digested food of the host is absorbed through the body wall. 


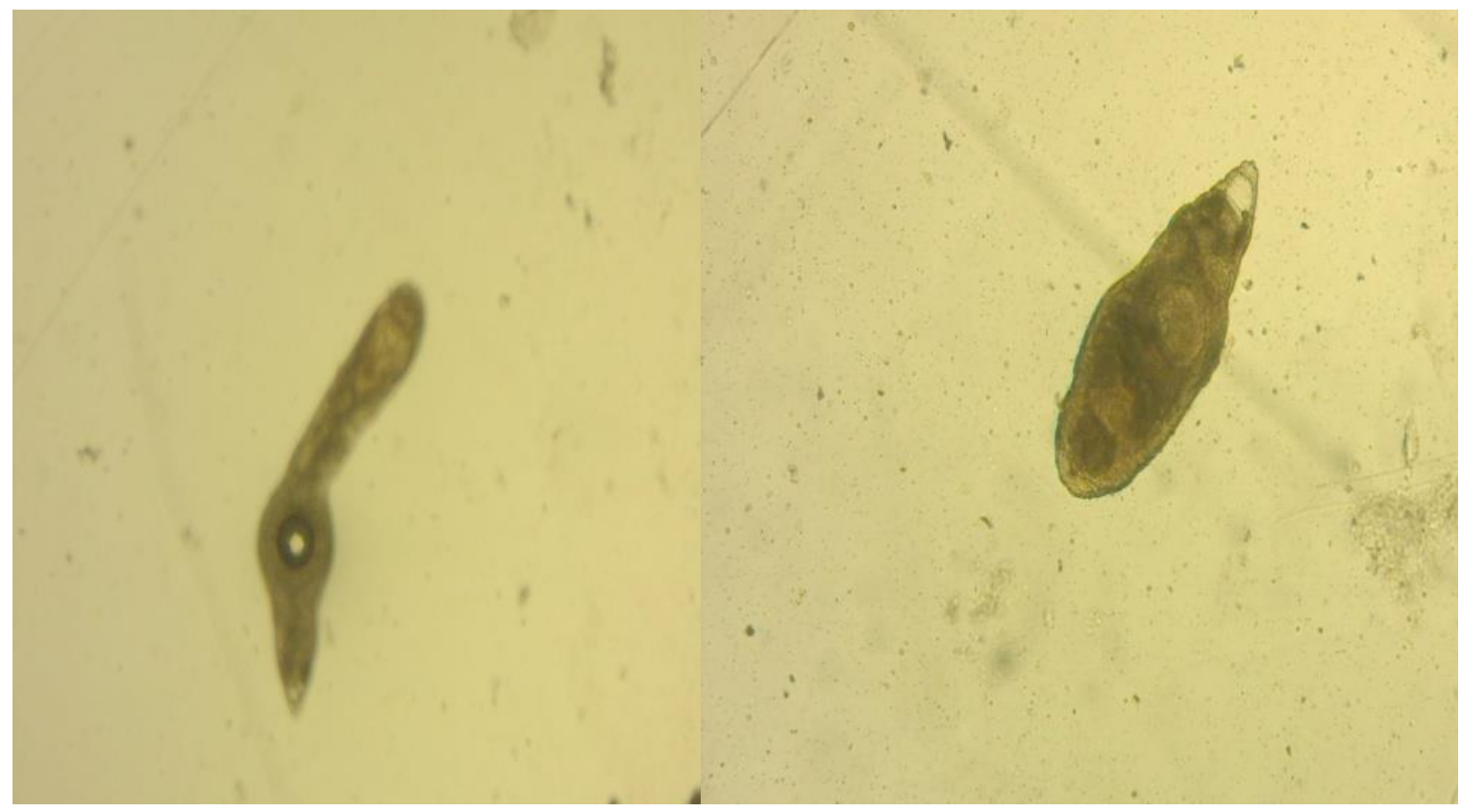

Fig 2: Cestode found in stomach and intestine

Two acanthocephalan, two platyhelminth were found. These parasites were found in the kidney, stomach, intestine, gill area.

\section{Characteristics of Acanthocephalan:-}

- Bilaterally symmetrical and vermiform.

- Body has thorny headed.

- Body cavity is a pseudocoelom.

- Body possesses no digestive tract.

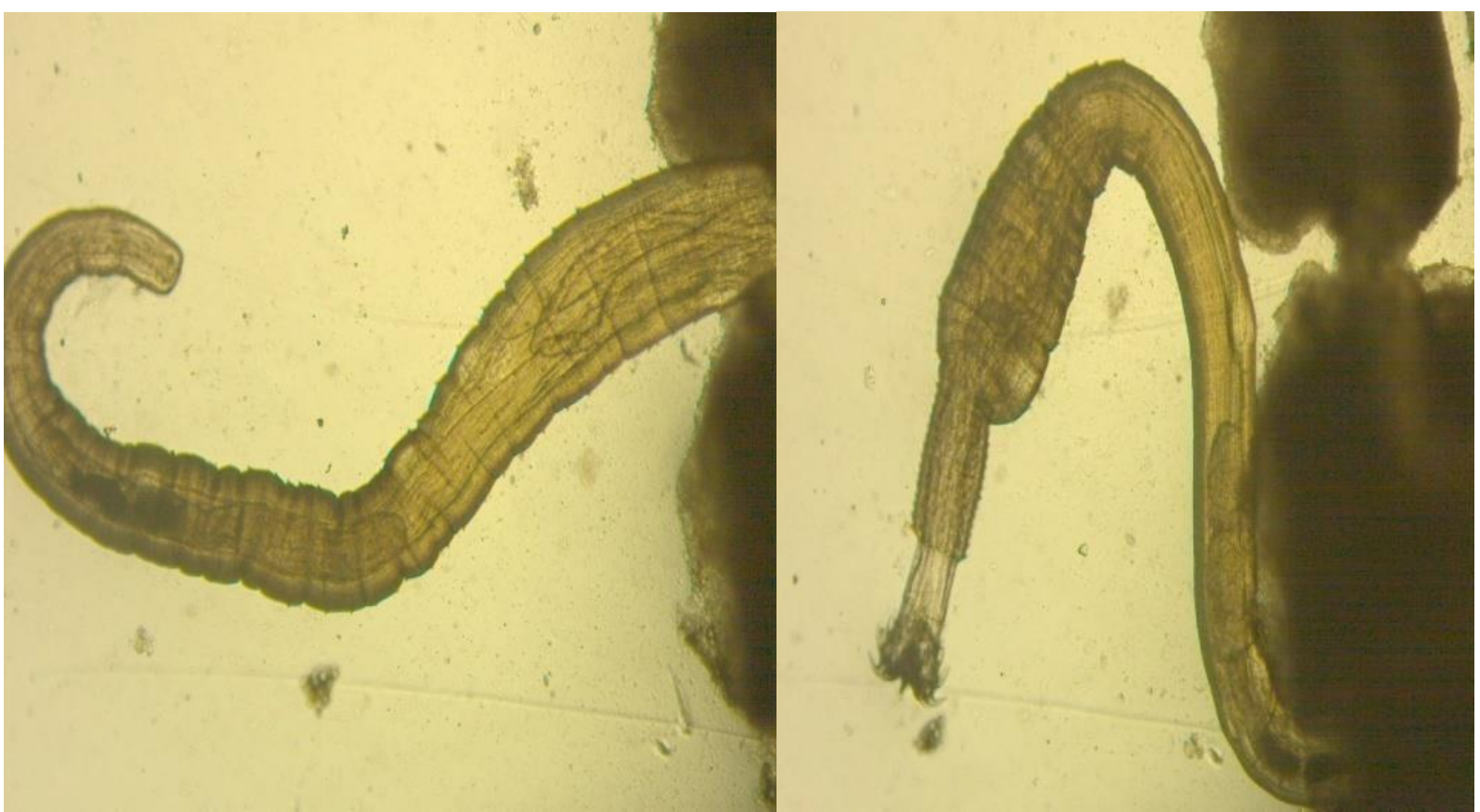

Fig 3: Acanthocephalan (Neoechinorhynchus rutili) in kidney of Channa punctata

\section{Characteristics of platyhelminth}

- Free-living and parasitic unsegmented worms that are dorsoventrally flattened (depressed).

- Triploblastic, acoelomate, bilaterally symmetrical.
- Spiral cleavage.

- Complex gut, but still incomplete; gut reduced to absent in parasitic species. 


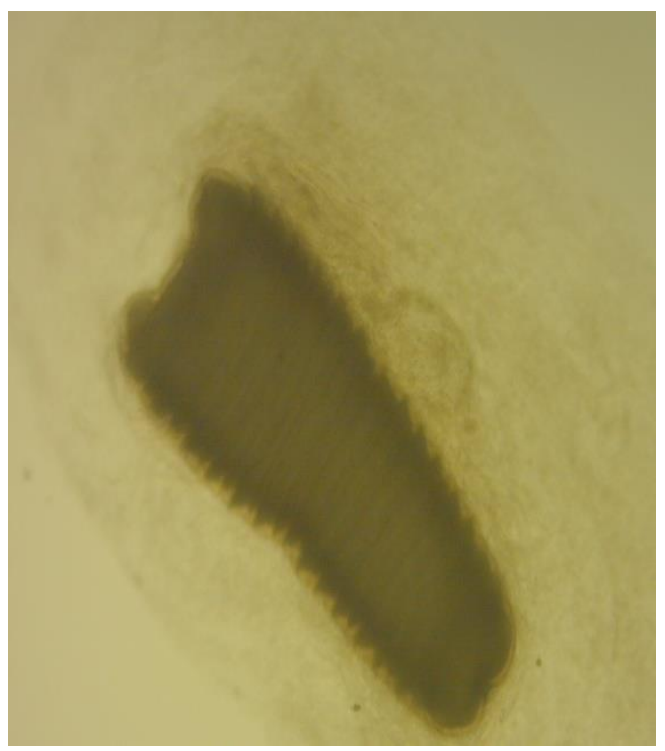

Fig 4: Platyhelminth (Monogenoideans) in intestine of Channa punctata

Liver cyst was also found in six fishes which is known as liver fluke. In the cyst there were live worm, which name is unidentified. Cyst, which is mainly formed by the presence of tapeworm like trematode and cestode.

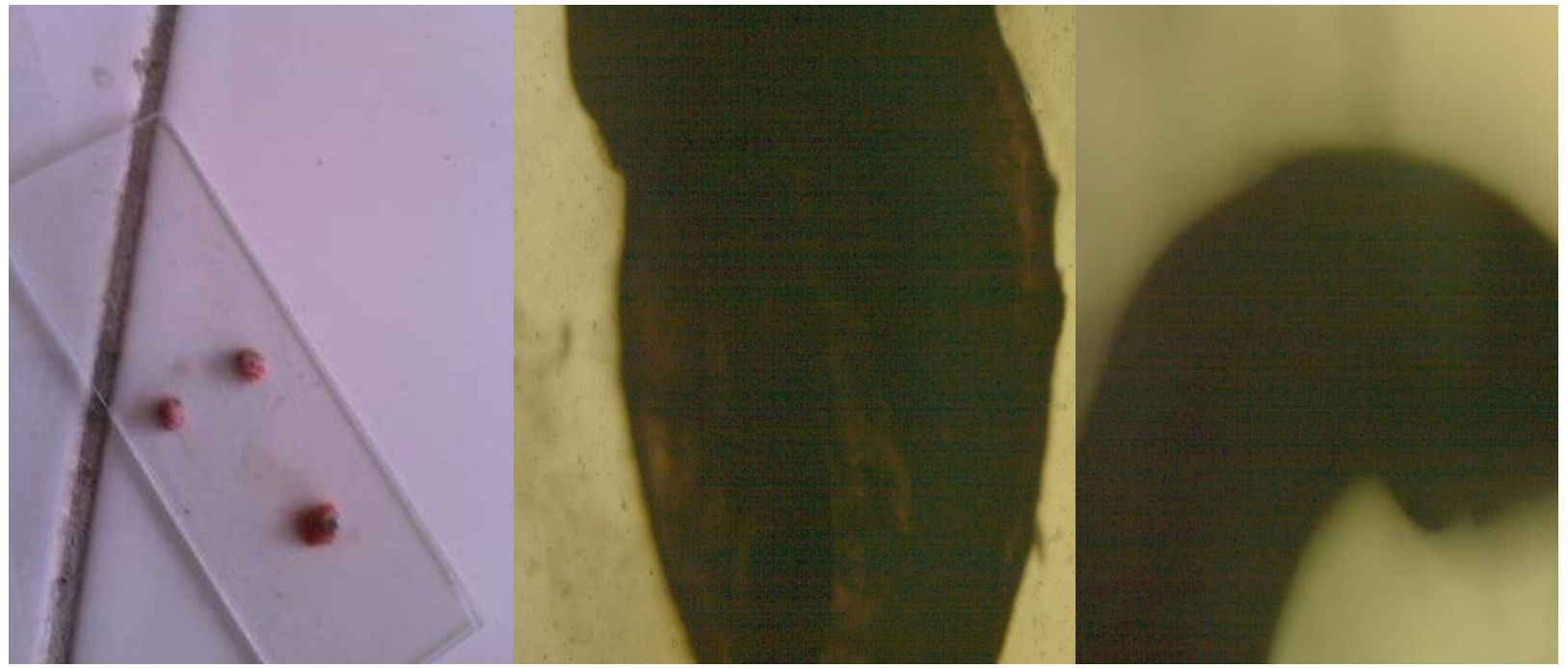

Fig 5: Liver cyst worm (Opisthorchis viverrini) of Channa punctata

\section{Characteristics of liver cyst worm (Opisthorchis viverrini)}

- $\quad$ Encysted metacercariae. Scale bar indicates $30 \mu$.

- Metacercariae released from cyst.

- Carmine-stained adult worm.
All the parasites were examined under a photographic microscope by adjusting the light to higher and lower.

\subsection{Data Analysis}

Table 1: Parasitocoenosis of Channa punctatus in Jessore, Bangladesh

\begin{tabular}{|c|c|c|c|c|}
\hline No. of fish & Weight (kg) & Length $(\mathbf{c m})$ & Site of infection & Name of parasites \\
\hline 01 & 29.20 & 10.09 & Intestine, liver, kidney & Absent \\
\hline 02 & 30.33 & 11.9 & Intestine & Absent \\
\hline 03 & 28.32 & 11.5 & Liver & Absent \\
\hline 04 & 29.40 & 11 & Liver & Absent \\
\hline 05 & 30.96 & 11.2 & Gill & Absent \\
\hline 06 & 26.42 & 9.20 & Intestine & Absent \\
\hline 07 & 25.20 & 8.10 & Spleen, gill & Absent \\
\hline 08 & 28.07 & 9.10 & Liver & Absent \\
\hline 09 & 27.45 & 9.3 & Kidney & Absent \\
\hline 10 & 28.75 & 9.9 & Intestine & Nematode \\
\hline 11 & 28.4 & 8.8 & Liver & Intestine \\
\hline 12 & 51.34 & 16.1 & &
\end{tabular}




\begin{tabular}{|c|c|c|c|c|}
\hline 13 & 46.30 & 15.1 & Intestine & Nematode \\
\hline 14 & 51.30 & 16.1 & Stomach & Nematode \\
\hline 15 & 42.34 & 15.3 & Stomach & Nematode \\
\hline 16 & 42.96 & 15.2 & Intestine & Nematode \\
\hline 17 & 36.20 & 15 & Stomach & Nematode \\
\hline 18 & 31.66 & 14 & Intestine & Nematode \\
\hline 19 & 13.92 & 10.4 & Stomach & Nematode \\
\hline 20 & 35.19 & 14 & Intestine & Nematode \\
\hline 21 & 33.30 & 10 & Stomach & Nematode \\
\hline 22 & 24.08 & 15.9 & Intestine & Nematode \\
\hline 23 & 33.68 & 15 & Stomach & Nematode \\
\hline 24 & 38.94 & 15.8 & Intestine & Nematode \\
\hline 25 & 36.33 & 15.9 & Intestine & Cestode \\
\hline 26 & 43.56 & 16.5 & Stomach & Acantocephalan \\
\hline 27 & 32.96 & 11.2 & Gill & Absent \\
\hline 28 & 34.55 & 11.4 & Intestine & Platyhelminth \\
\hline 29 & 45.60 & 15.1 & Kidney & Acanthocephalan \\
\hline 30 & 43.76 & 15.2 & Spleen & Absent \\
\hline 31 & 44.50 & 15.4 & Intestine & Platyhelminth \\
\hline 32 & 34.76 & 11.9 & Liver & Liver fluke \\
\hline 33 & 46.30 & 15.8 & Liver & Liver fluke \\
\hline 34 & 33.7 & 15.1 & Liver & Absent \\
\hline 35 & 43.7 & 15.2 & Liver & Liver fluke \\
\hline 36 & 35.5 & 14 & Liver & Liver fluke \\
\hline 37 & 43.8 & 15.2 & Intestine & Absent \\
\hline 38 & 35.9 & 15.1 & Stomach & Absent \\
\hline 39 & 33.6 & 15 & Liver & Liver fluke \\
\hline 40 & 24.08 & 15.9 & Kidney & Absent \\
\hline 41 & 33.68 & 15 & Liver & Liver fluke \\
\hline 42 & 38.94 & 15.8 & Intestine & Nematode \\
\hline 44 & 36.33 & 15.9 & Stomach & Nematode \\
\hline 45 & 43.56 & 16.5 & Kidney & Absent \\
\hline 46 & 32.96 & 11.2 & Intestine & Nematode \\
\hline 47 & 36.20 & 15 & Intestine & Nematode \\
\hline 48 & 31.66 & 14 & Gill & Absent \\
\hline 49 & 13.92 & 10.4 & Intestine & Absent \\
\hline 50 & 32.56 & 11 & Gill & Absent \\
\hline
\end{tabular}

Now the highest incidence of parasite infection are shown in a pie graph

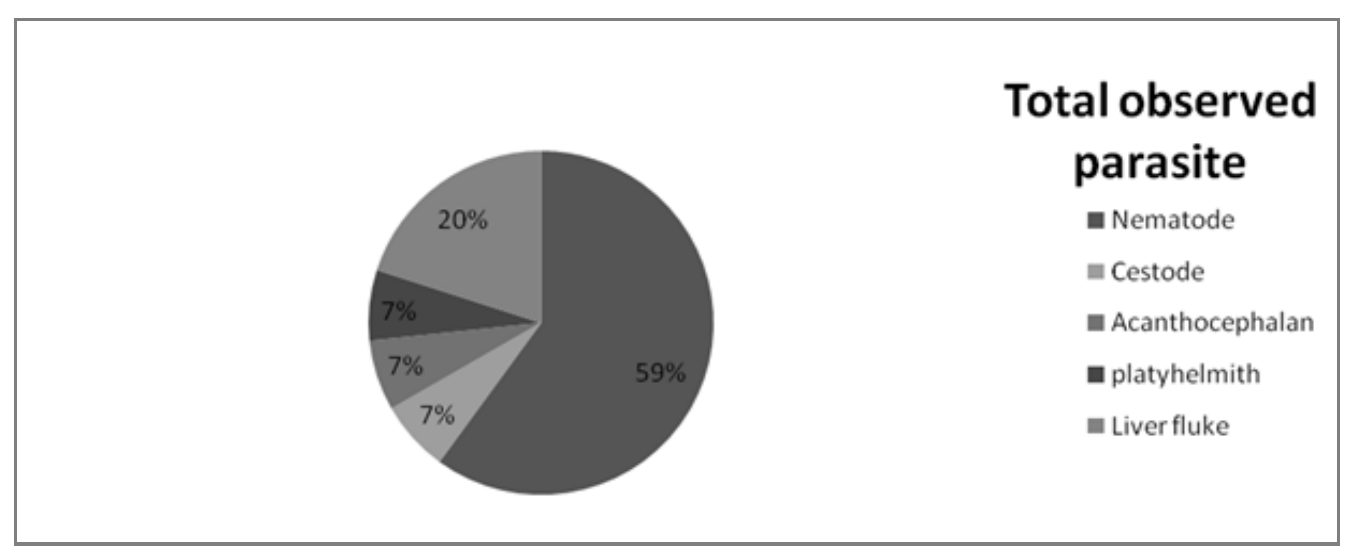

Fig 6: The incidence of different parasite groups of Channa punctatus collected from different water body.

\section{Discussion}

In this experiment all the $C$. punctata were collected from different village around the jessore city. The fishes which were collected from the cultured pond or fish farm found less parasitic attack compare the fishes which were collected from lake and baor. The fishes which were encountered by the parasites looked very unhealthy. Nematode, cestode, acanthocephalan, platyhelminth and liver fluke were isolated from intestine, liver, stomach, kidney and gill. Therefore the juvenile fish had no parasite while the sub-adults and adults had higher prevalence this implies that infestation increased with age of fish and again the lower prevalence rate of adult fish to parasitaemia might be due to the fact that adult fish may have acquired immunity as a result of an earlier exposure to parasites and other factors ${ }^{[7]}$. Both prevalence and intensity were higher in the rainy season (April-August) and in larger fish. The parasitic burden was more evident in gravid females. The host diet and availability of infective larval stages are 
thought to influence the number of parasites ${ }^{[11,12]}$.

The comparison of the micro parasite communities among the different village area of jessore city is fairly high ${ }^{[4]}$. Among the fifty experimental fishes eighteen (18) nematodes, two (2) cestodes, two (2) acanthocephalan, two (2) platyhelminthes and six (6) liver fluke were found. Some of the nematodes and liver fluke worm can be seen with the naked eye. Adult nematodes are typically found in fish digestive tracts. However, depending upon the species of nematode and the species of infected fish, adult and other life stages of nematodes can be found in almost any part of the fish, including the coelomic (body) cavity, internal organs, and the swim bladder, deeper layers of the skin or fins, and external muscle layers ${ }^{[8]}$. Small numbers of nematodes may be present in fish without causing significant symptoms [9]. Depending upon the species of fish and the species of nematode, fish may be final hosts (containing adult nematodes) or intermediate hosts (containing larval nematodes). Some species of nematodes that infect fish can be transmitted directly from one fish in the population to another (direct life cycle). Other species of nematodes require additional hosts to complete their life cycle, commonly an invertebrate host or a fish, bird, or mammal as final host. Consequently, correct identification of the nematode is critical for proper management of the disease [10]. Liver fluke is mainly occurred in the presence of tapeworm like trematode, cestode. Liver fluke are mainly transferred by eating raw fish or marinated fish which is now very available in our country. The results of this study demonstrate that the human liver fluke $O$. viverrini is endemic to many foreign countries and that it is being naturally transmitted to fish species that are often consumed raw or inadequately cooked. For determination of the prevalence, distribution, and epidemiology of $O$. viverrini flukes in fish, humans, and reservoir hosts (e.g., cats and dogs), these results need to be extended, especially because aquaculture is a growing industry in Bangladesh. Carps are often eaten raw, marinated, or lightly cooked ${ }^{[13]}$. In contrast, infected barb (Puntius brevis) and rasbora (Rasbora spp.) fish are not eaten raw and barb fish are invasive in farm fish ponds and can persist as a self-recruiting species; the presence of barb is an indication that pond management is insufficient to prevent invasive species of fish ${ }^{[14]}$. Furthermore, barb fish are often fed to farm cats, which are major reservoir hosts for fishborne liver and intestinal trematodes ${ }^{[15]}$. Infections in snakehead fish (Channa spp.) also represent a food safety risk, because snakehead fish are cultured in many foreign countries and are sometimes eaten raw or inadequately cooked. In addition to $O$. viverrini flukes, metacercariae of the zoonotic intestinal flukes [13].

\section{Conclusions}

Channa punctatus are mostly infected by nematodes and cestodes parasites. Nematodes and acanthocephalans are intestinal parasites. Acanthocephalans parasitic infestation was poor in Channa punctatus. Liver fluke is assumed to be a new parasite for Channa punctatus which requires a detailed micro and macro environmental description. These parasitic groups are not listed in any parasitic study of Channa punctatus before. Both prevalence and intensity are higher in the rainy season (April-August) and in larger fish. The parasitic burden is more evident in gravid females. As most of the helminth parasites are found in the digestive tract and it is occurred because of variety of diet. Before having any minimal loss proper protection need to enhance by regular monitoring of water quality, feeding habit and physio-environmental condition.

\section{References}

1. Harris KK, Gupta AK, Agrawal SM. Pathophysiology of Epizootic Ulcerative Syndrome in Channa punctatus. Journal of Parasitology and Applied Animal Biology 1992; I(2):125-130.

2. Hussain MG. Freshwater fishes of Bangladesh: Fisheries, biodiversity and habitat. Aquatic Ecosystem Health \& Management 2010; 13(1):85-93.

3. Doglel VA, Petrushevski GK, Polyansky YI. Parasitology of Fishes, Oliver and Boyd, London, UK, Translated by (Kabata), 1961.

4. Srivastava SJ, Singh R. Seasonal changes in the testes of a freshwater murrel, Channa punctatus. Naturalia 1994; 19:119-130.

5. Chandra KJ. The anatomy and histology of the alimentary tract of perch, Perca fluviatilis (L.). Progressive Agriculture 1998; 9:157-62.

6. Afroz T, Nabi MR, Mustafa G. The morphohistology of alimentary canal of Chapila, Gudusia chapra. Bangladesh Journal of Zoology 1999; 27:51-55.

7. Auta J, Oniye SJ, Adakole. The helminth parasites of the gastrointestinal tracts of Synodontis species in Zaria, Nigeria. Zuma J Pure Applied Sci 1999; 2:47-53.

8. Measures LN. The development of Eustrongylides tubifex (Nematoda: Dioctophymatoidea) in oligochaetes. Journal of Parasitology 1988; 74(2):294-304.

9. Noga EJ. Fish disease: diagnosis and treatment. MosbyYear Book, Inc., St. Louis, MO, 1996, 166-170.

10. Yanong RPE. Nematode (Roundworm) Infections in Fish. Edn 1, University of Florida, USA, 2002.

11. Russo JR, Yanong RPE. Molds in fish feeds and aflatoxicosis. FA95. University of Florida IFAS Cooperative Extension Service, 2002.

12. Svobodova Z, Karova J, Machova BV, Hamackova J, Kouril J. Basic haematological parameters of African catfish (Clarias gariepinus) from intensive warm-water culture. Res Inst Fish Culture Hydrobiol 1994; 389:6-6.

13. Khalil LF, Polling L. Checklist of the helminth parasites of African freshwater fishes. University of the North, Republic of South Africa. River Printers, Pieterburg, South Africa, 1997, 185.

14. Chai JY, Murrell KD, Lymbery AJ. Fish-borne parasitic zoonoses: status and issues. Int J Parasitol 2005; 35:123354.

15. Thaenkham U, Nuamtnong S, Vonghachack Y, Yoonuan T, Sanguankiat S, Dekumyoy P. Discovery of Opisthorchis lobatus (Trematoda: Opisthorchiidae): new recorded species of small liver flukes in the greater Mekong sub-region. J Parasitol 2011; 97:1152-8.

16. De NV, Murrell KD, Congle D, Cam PD, Chaule V, Toan ND. The food-borne trematode zoonoses of Vietnam. Southeast Asian J Trop Med Public Health. 